\title{
Prevalence and Patterns of Divorce in Vietnam: Tradition, Modernity, and Individualism
}

\author{
Tran Thi Minh Thi \\ Viet Nam Academy of Social Sciences, Ha Noi, Viet Nam
}

\begin{abstract}
In Vietnam, divorce traditionally was considered scandalous for women, so there was a strong pressure against divorce, especially for women. While divorce has long been culturally discouraged and limited, divorce has been rapidly increasing after the renovation policy in late 1980s with alternative causes, consequences, etc. Modernization is a process of transforming "traditional" society to "modern" one, in order to achieve economic development and growth, to innovate politics and to enhance their social structure towards a political, social, and economic system similar to those of western developed countries. In the field of marriage, family, and kinship, modernization process experiences the maintenance of traditional values and the appearance of the new modern values. This paper aims to examine trend and correlates of divorce and to identify social and cultural factors influencing the divorce decision, using data of divorce profiles of one district court in 10 years (i.e., 2000-2009) with total divorce profiles analyzed are 2,033 cases, of which 499 divorce couples in a rural district and 1,534 divorced couples in an urban area.
\end{abstract}

Keywords: divorce, incidence, causes, Vietnam, tradition, modernity, modernization, collectivism, familialism, individualism

\section{Introduction}

In the last several decades, marriage and family in Vietnam experienced the significant transition from the traditional style to more modern characteristics. Traditional patterns of arranged marriage, gender inequality, strong patriarchy, and many children under the Confucian cultural heritage significantly declined. In addition, the models of the extended family, strong son preference, the important roles of the kinship system, dominant male household head, etc. are transitional substantially.

Under the impacts of socio-economic and political changes, legal institution changes, and international integration, marriage, family, and women's status experienced great progress. The arranged marriage declines dramatically while the love marriage base on free mate selection increased (Le Ngoc Van, 2006; Nguyen, 2008). Marriage is still universal in Vietnam but age at marriage is gradually increasing. Patrilocal co-residence is common currently but the family relations among members are more liberal. Although patriarchy is strong, women have substantial decision-making power within the family and it is perceived that this power has increased (Nguyen, 2011). Male head of family has diversified, reflecting changes in family structure but there is

Tran Thi Minh Thi, Ph.D., Deputy Director, Institute for Family and Gender Studies, Viet Nam Academy of Social Sciences. 
an increase in the number of female-headed. Gender equality protection, two child policy, expansion of educational and employment for women, as well as the significant contribution of women in the labor force have greatly promoted women's role and status in the society.

While divorce has long been culturally discouraged and limited, divorce has been rapidly increasing after the renovation policy in late 1980s with alternative causes, consequences etc. However, very few empirical studies, which are based on statistical analyses of individual data on the association between socio-demographic factors and divorce in Vietnam, have been published. Using the results of the existed data, which include Vietnam censuses 1989, 1999, and 2009; the annual statistics on divorces at the Vietnam Supreme Court; and especially, the whole divorce cases granted at two district courts in ten years 2000-2009 in the Red River Delta (i.e., 2,033 divorced cases, of which 499 divorced couples in a rural district and 1,534 divorced couples in the urban district); this paper attempts to examine the prevalence and patterns of divorce under the forces of tradition, modernity, and modernization.

A divorce court record is noted in two profiles: the Annual Divorce Entry Registration and the Annual Divorce Court Results. The former provides the basic general information of the couples who apply for divorce such as date of divorce application registration, information of the initiative person (name, sex, year of birth, address), information of the dependent spouse (name, sex, year of birth, address), marriage year, divorce year, reported causes of divorce, number of child, and other professional notes of the court. In general, this Registration profile can provide with the basic demographic and social variables for the study.

However, not all cases in the Annual Divorce Entry Registration subject to divorce due to divorce application cancel under the reconciliation process or due to marital problems resolving among the couples themselves. Therefore, at the same time, the recoded and computerized process must double check and uses the Divorce Court Result as the most important resource for data collection. Only couples who were granted divorce under the divorce decision are included in this analysis. In the divorce decision, the following information are included: date of entry registration; date of decision; information of the initiative and the spouse (name, sex, year of birth, address...); number of children, and divorce decision of child custody arrangement, house arrangement, property arrangement (if required), subsidy after divorce, debt responsibility, and court fee. For the first time in Vietnam, the whole divorced population in a period of 10 years are processed which can provide the comprehensive trends, characteristics, and determinants of divorce.

\section{Theoretical Approaches}

\section{Tradition, Modernity and Modernization}

Together with social changes, societies transformed from tradition to modernity. Theorists developed the modernization theory to explain the social changes, for example, divorce; in modernity. Previous literature argues that modernization has two opposing forces to divorce. Socioeconomic development, together with modernization and urbanization, may first reduce divorce rates but, at later stages of modernization, increase the incidence of divorce. Several social changes associated with modernization can account for the decline in divorce including the rise of conjugal family systems, increasing autonomy of youngsters and increased freedom from extended kin control, increasing age at marriage, educational expansion, urbanization, and greater freedom in mate selection (Goode, 1963, 1971, 1993; Hirschman \& Teerawichitchainan, 2003; Jones, 2003; Lee, 1982). 
Women's gained status may initially slow the incidence of divorce. However, most theorists suggest that in the long run the trend toward egalitarianism that accompanies modernization and the replacement of patriarchalism has the opposite effect. The destabilizing force of female empowerment is accommodated by Goode's $(1963 ; 1993)$ theory that treats modernization as the root case for elevated divorce rate. Improvements in women's status create a socio cultural environment that makes divorce more easily attainable. Increasing economic independence of women, smaller families, and ideological emphasis on self-fulfillment with relationships and individual choice may shift the tide toward less stable relationships. Industrialization may reduce the size of families and, hence, in-crease the likelihood of divorce, independent of its effects on women's social position. Modern marriage based on love and affection may be more unstable than one based on socioeconomic or other needs.

In Vietnam, modernization is a process of transforming "traditional" society to "modern" one, in order to achieve economic development and growth, to renew politics and to enhance the social structure towards a political, social, and economic system similar to those of western developed countries, has increased individual freedom and opened up social opinion on divorce. The traditional Vietnam referred to the feudal and colonial periods before 1945 and modern Vietnam referred to the direct transformation to socialism, skipping capitalism. This kind of shortcut modernity not only refers to the skipping of capitalist industrialization but also reflects one main feature of modernization and industrialization in Vietnam, which is the "shortened" strategy, which implies that it is a process of transforming from agricultural economy to industrial economy and take advantages of "behind goer" as a lately industrialized country. The shortcut modernity is actually a social situation in which the dynamic coexistence of mutually traditional and modern elements leads to the construction of the market-oriented socialism system, of the process of the maintenance positive traditional values and the perception of new values and knowledge in the international integration context. The unique feature of shortcut modernity of contemporary Vietnam comprise both feature of first modernity (i.e., ideology of full employment and connected to the achievement/accomplishment principle in work; nuclear families, a collective solidarity), and second modernity (i.e., industrialization, market economy, and cultural globalization), according to Beck (1992); and compressed modernity in terms of mutual disparate coexistence of various levels of human existence and transitional values that new institutions have not perfected while old institutions remain existent, according to Chang (2010).

The state plays the important roles in modernization process. The effects of state and modernization forces may operate through different but related mechanisms. Modernization forces influence marriage and divorce patterns mostly through economic development the expansion of education and occupation and cultural communication via globalization process. It is noted that the Vietnamese government plays the important roles in marriage pattern formulation through the introduction of policies and laws on marriage and family, and other socioeconomic development policies. Laws, regulations, mass mobilization, and propaganda campaigns regarding marriage directly affect individual marital behaviour, whereas, socioeconomic policies which facilitate or slow down the modernization process are indirect influences of the state. The policy changes are parallel with the economic development and modernization but in fact, the unique power of the communist party and the government in functioning the entire society, the state placed the foundation for all social changes, including marriage and family changes. 
Modernization process in Vietnam experiences the maintenance of traditional values and the appearance of the new modern values. From the socio-economic crisis in early 1980s to the market economy and open door policy since late 1980s, the state's approach to family matters had to adapt to processes of resistance and negotiation in which families actively engaged and did encompass fundamental changes that have altered family relations, practices, and behaviors, of which, families could contest change and retain values. Through processes of contestation, adaptation, resistance, and negotiation, families turned the transition into a daily reality. The renovations vividly illustrate how families propelled and made possible the transition, while living in continuity with the past (Barbieri \& Belanger, 2009). Nuclear and stem families are increasing while the extended family patterns never disappeared completely. Unskillful young and old labors are unemployed or work in the agricultural sector with low productivity and income while work opportunities for women increase; they can look for jobs outside their houses, and they can more and more actively take part in socio-economic life. Women still suffer from domestic violence but gain more independence in terms of economic contribution and marriage and family relations. Marriage is universal, familialism remains significant but individual freedom increases, in the context that informal control of families and kinship on individuals are weaken due to the pressure of social and residential mobility. With the influences of urbanization and modernization, institutional settings of laws and policies, and the comprehensive international integration, marriage, family, and population in Vietnam are deeply in transition, where old and new values as the competing forces are operating. In the theoretical groundwork for liberalism and the market economy oriented socialism, individualistic culture is believed to increase in Vietnam.

\section{Collectivism, Familialism, and Individualism}

The understanding of the notion of collectivism [tính tập thể, tính cộng đồng,] and individualism [tính cá nhân] in the relation with familialism and modernization is manifested in interpretation of disparate marriage and family behaviors in contemporary Vietnam. Family is a fundamental unit of Vietnamese society and is in the center in the relation of individuals with the community and the state. Vietnamese families are usually divided into two basic forms, which are traditional and modern family. Traditional family is among the common term when discussing about Vietnamese society, which refers to family forms prevailing during the presocialist period, so mostly prior to the 1950s. It is believed that there was strong patriarchal familialism in the presocialist period, which considers family an organization with same destiny, family members are compelled to satisfy themselves for common interest of the family. In other words, they widely believe that a single member can be satisfied for others within the family. This patriarchal familialism puts priority on the overall well-being and prosperity of the family over individual freedom or autonomy. As the feudal system collapsed, patriarchal familialism gradually degraded, leading up to a couple-centered structure and a gender-equal small family system, as seen in the capitalist system, and in the shortcut to socialism in Vietnam. The notion of modern marriage and family was set up with several features, for instance, familialism remains significant but individualism increases.

The close ties between the extended families and communities can have a major influence on individual behaviour. The reason is, the patriarchal familialism has organized toward the lineage and community spirits in the collectivist culture. In the other words, collectivism goes beyond the familialism in formulation of the 
marriage and family behaviors. The collectivist culture of Vietnam rooted from the Confucian ideology, which is strongly orientated around family and community. The notion of collectivism in almost aspects of life was even promoted for general generations due to the demand of strong collective will and power in the fierce struggles to fight for the nation liberty and independence in centuries.

A recent study on collectivism and individualism in Vietnam showed that despite cross cultural interactions, collectivism prevailed over individualism among Vietnamese as compared with other nationalities such as Americans, Japanese, and Koreans in early 2000s. However, the dimension of collectivism and individualism varied according to gender, situations, and sub-cultures of geographical regions. Generally speaking, Vietnamese women are found to be more collectivist than men, but these two variables are complicated when it comes to different sub-cultures of the North and the South, rural and urban areas, the Kinh (the main race of Vietnam) and other minority people. Moreover, collectivism and individualism in the Vietnamese value system differ substantially from behaviors in actual situations (Do \& Phan, 2002).

In the field of marriage, family, and kinship, modernization process experiences the maintenance of traditional values and the appearance of the new modern values. Family is a fundamental unit of Vietnamese society. Nuclear and stem families are increasing while the extended family patterns never disappeared completely. The concept rooted from the socioeconomic crisis in 1980s to the market economy and open door policy. The state's approach to family matters had to adapt to processes of resistance and negotiation in which families actively engaged. Through processes of contestation, adaptation, resistance, and negotiation, families turned the transition into a daily reality. The renovations vividly illustrate how families propelled and made possible the transition, while living in continuity with the past (Barbieri \& Belanger, 2009). In the other words, with the influences of modernization, legal changes, and the comprehensive international integration, marriage and family in Vietnam are deeply in transition, where old and new values as the competing forces are operating. In the theoretical groundwork for modernization and the market economy oriented socialism, individualistic culture is believed to increase in Vietnam.

\section{Key Findings}

\section{Finding 1: Increase in Divorce Incidence}

The number of divorces is increasing gradually in Vietnam, and the upturn is much stronger in urban areas than in rural areas as can be seen in Figure 1. The numbers of divorces were almost unchanged in the 1960s and 1970s, which were around fifteen thousand cases per years. Divorce was slightly increasing in the following two decades 1980s and 1990s. Divorce has risen fast since the 2000s. In the beginning of the 2000's, there were 51,361 divorces in the whole country. This number has kept increasing and reached to about 100,000 cases in 2010, which is nearly double. The increasing trend shares with other Southeast Asian countries such as Indonesia, Malaysia, and the Philippines (Tran, 2010, 2011, 2014).

Similar to the pattern of divorce numbers, divorce rates are rising slightly in the entire Vietnam, although they remain relatively low compared to the rates of other developed countries and are similar to other Asian countries such as China and Singapore (Ochiai, 2011). In 2000, CDR was 0.66 and increased to 1.05 in 2009 (see Table 1). The GDR was rising from 0.97 in 2000 to 1.49 in 2010. 


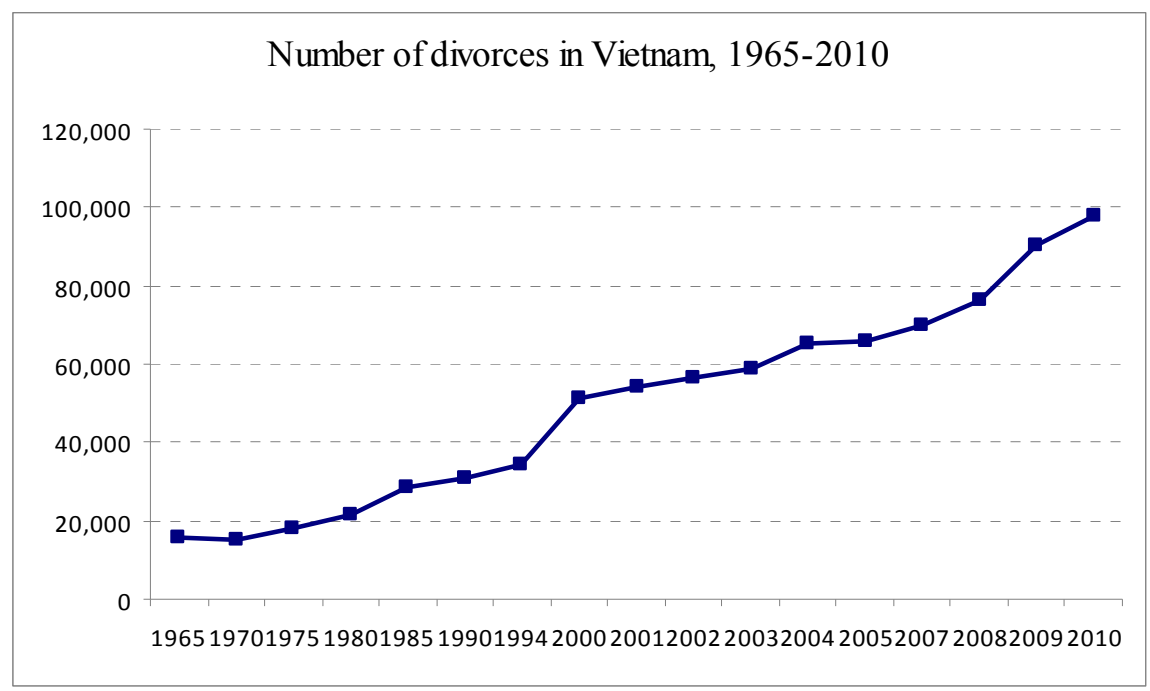

Figure 1. Number of divorces in Vietnam, 1965-2010. ${ }^{1}$

Table 1

Crude Divorce Rate and General Divorce Rate in Vietnam, 2000-2009²

\begin{tabular}{llllll}
\hline Year & Divorces* & Population** & CDR & Population $15+* * *$ & GDR \\
\hline 2000 & 51,361 & $77,630,900$ & 0.66 & $53,148,971$ & 0.97 \\
2001 & 54,226 & $78,685,000$ & 0.69 & $53,872,252$ & 1.01 \\
2002 & 56,487 & $79,727,000$ & 0.71 & $55,405,348$ & 1.02 \\
2003 & 58,708 & $80,902,000$ & 0.73 & $56,935,391$ & 1.03 \\
2004 & 65,336 & $82,031,000$ & 0.80 & $58,613,453$ & 1.11 \\
2005 & 65,929 & $82,393,500$ & 0.80 & $60,065,667$ & 1.10 \\
2006 & 67,058 & $83,313,000$ & 0.80 & $61,279,802$ & 1.09 \\
2007 & 69,646 & $84,221,100$ & 0.83 & $62,618,033$ & 1.11 \\
2008 & 76,490 & $85,122,300$ & 0.90 & $63,702,050$ & 1.20 \\
2009 & 90,092 & $86,025,000$ & 1.05 & $64,948,875$ & 1.39 \\
2010 & 97,627 & $86,932,500$ & 1.12 & $65,311,641$ & 1.49 \\
\hline
\end{tabular}

Modernization accompanied by the infiltration of egalitarianism, the improvement of women's socio-economic status, and the expansion of individualism explains, to some extent, the increasing number of divorce in Vietnam. State policies and strategies on marriage, family, population, and gender equality; socioeconomic development with the accelerating modernization and industrialization; and the international integration of socio-culture and mass media institutional settings with the increasing individualization are significant. Divorce in the 1960s and 1970s was influenced by the Constitution and the first Law on Marriage and Family 1959, which banned arranged and child marriage, promoted gender equality, protected women's basic rights of property ownership and divorce; was enacted. The law officially ended feudal marriage and introduced modern marriage based on love and intimacy. It is noted that Vietnam War in that period could limit the law communication and effectiveness on the marriage and family. Also individuals of several generations were called

\footnotetext{
${ }^{1}$ Source: Vietnam: Author's calculation from Statistics of Supreme Court of Vietnam.

2 Source: Author's calculation based on: *Supreme Court of Vietnam: Annual Statistics; **GSO: Statistical Year Book of Vietnam 2000-2010; ***: GSO and UNFPA. Data Warehouse on Annual Population Change and Family Planning Survey.
} 
to serve the country's fight for independence and unification as the number one priority and marriage and family should be after the collective priorities.

A key argument is that divorce was a taboo before Renovation (Doi moi). After the late 1980s, Vietnam was modernized rapidly, which included trends in increased age at marriage, expansion of educational opportunities, high proportion of female participation in the labor market, greater freedom among young people to choose their marital partners and increased individualization intimacy. In addition, the government has provided alternative institutional settings with favored gender equality, which enhances and empowers women's role and status. Globalization may also lead to changing attitudes towards less traditional forms of relationships and family. It appears that social changes associated with modernization have eroded traditional norms, which might explain rises in divorce in many settings. Increased economic independence of women, smaller family size, and ideological emphasis on self-fulfillment with relationships and individual choice may shift the tide toward less stable relationships. Renovation 1986 marked the fundamental changes to marriage and family. After several decades of legal constructions of gender equality, education, health, marriage, family, population, social perception of new values in marriage and family such as freedom in mate selection, intimacy, women's rights, and individualism constitutes more prevailed. As individual become more liberal in their marital decision, and social opinions towards divorce become more open as the results of modernization, divorce is easier to attain.

\section{Finding 2: There Is Evidence That Divorces Occur More Often Among Younger Couples, Among Young People, Especially Among Those in More Traditional Settings Such as Rural Areas. This May Suggest a Higher Level of Individualism in Vietnam}

As for the average age at divorce, women divorce at younger ages than men. In total, mean age at divorce of men is 38 and of women is 34.4 , which is 3.6 year differential. The sex differential of the age at divorce is similar to the age at marriage pattern. It is interesting that the age at divorce of rural women is about 4.5 years earlier than urban women and rural men also report about 5 year younger of age at divorce compared to the urban men. In general, both of men and women in the rural areas divorce at quite younger ages than the urban counterpart.

In addition, rural individuals divorce at younger ages than their urban counterparts. In the urban areas, women can break off their marriage even in their middle age to start a new life. In the rural areas, younger women also divorce at younger age than urban women, which may suggest that rural women are becoming increasingly open to divorce. In particular, the mean age at divorce of rural women is 31 for rural women and 34.3 for rural men. The mean age is 35.5 for urban women and 39.2 for urban men. Among rural individuals, men often divorce from 32-36 years old and women often divorce from 29-33 years old. The rural sex differential ranges from 2.5-4.7 years. Among urban divorced, men often divorce from 38-40 years old and women often divorce at 34-36 years old. The urban sex differential ranges from 3-4 years. Recently, mean age at divorce in urban are larger, which means more urban women get divorce at younger ages. Whereas, mean age at divorce of rural women somehow have no change. Urban couples are also expected to be more educated and have skills to maintain happiness as well as to handle the marital problems (see Table 2). 
By the age of 34 , about $59.7 \%$ of women divorce, by the age of $40,77.2 \%$ of women divorce, and by the age of $47,90 \%$ women divorce. Among divorced men, by the age of 38, about $59.5 \%$ men divorce, and by the age of $50,90 \%$ of husband divorce (see Figures 2 and 3). It can be explained that, the effects of modernization are increasing in both rural and urban areas. In the urban areas, women can break their marriage even in the middle ages to start their new life. In the rural areas, younger women also divorce at younger age than urban women, which means rural women are more and more open to divorce.

Table 2

Mean Age at Divorce by Years ${ }^{3}$

\begin{tabular}{llllllllll}
\hline $\begin{array}{l}\text { Year of } \\
\text { divorce }\end{array}$ & Rural men & $\begin{array}{l}\text { Rural } \\
\text { women }\end{array}$ & $\begin{array}{l}\text { Rural sex } \\
\text { differential }\end{array}$ & Urban men & $\begin{array}{l}\text { Urban } \\
\text { women }\end{array}$ & $\begin{array}{l}\text { Urban sex } \\
\text { differential }\end{array}$ & Total men & $\begin{array}{l}\text { Total } \\
\text { women }\end{array}$ & $\begin{array}{l}\text { Total sex } \\
\text { differential }\end{array}$ \\
\hline 2000 & 34.8 & 32.2 & 2.6 & 39.6 & 36 & 3.6 & 37.9 & 34.7 & 3.2 \\
2001 & 34.8 & 32.3 & 2.5 & 39.6 & 36.7 & 2.9 & 38 & 35.2 & 2.8 \\
2002 & 32.3 & 28.5 & 3.8 & 38.3 & 35.1 & 3.2 & 36.2 & 32.8 & 3.4 \\
2003 & 35.2 & 32.1 & 3.1 & 40.4 & 36.4 & 4 & 38.7 & 35 & 3.7 \\
2004 & 32.9 & 29.4 & 3.5 & 40 & 36 & 4 & 37.9 & 34.1 & 3.8 \\
2005 & 33.1 & 30.4 & 2.7 & 38 & 34.6 & 3.4 & 37 & 33.8 & 3.2 \\
2006 & 35.7 & 31 & 4.7 & 38.3 & 34.8 & 3.5 & 37.8 & 34 & 3.8 \\
2007 & 32.7 & 28.9 & 3.8 & 40.1 & 35.9 & 4.2 & 38.5 & 34.4 & 4.1 \\
2008 & 36.2 & 33.1 & 3.1 & 39.4 & 35.7 & 3.7 & 38.6 & 35 & 3.6 \\
2009 & 35.2 & 32 & 3.2 & 39.3 & 35.1 & 4.2 & 38.7 & 34.6 & 4.1 \\
Total & 34.3 & 31 & 3.3 & 39.2 & 35.5 & 3.7 & 38 & 34.4 & 3.6 \\
$\mathrm{~N}$ & 499 & 499 & & 1530 & 1530 & & 2029 & 2029 & \\
\hline
\end{tabular}

Age at divorce of women

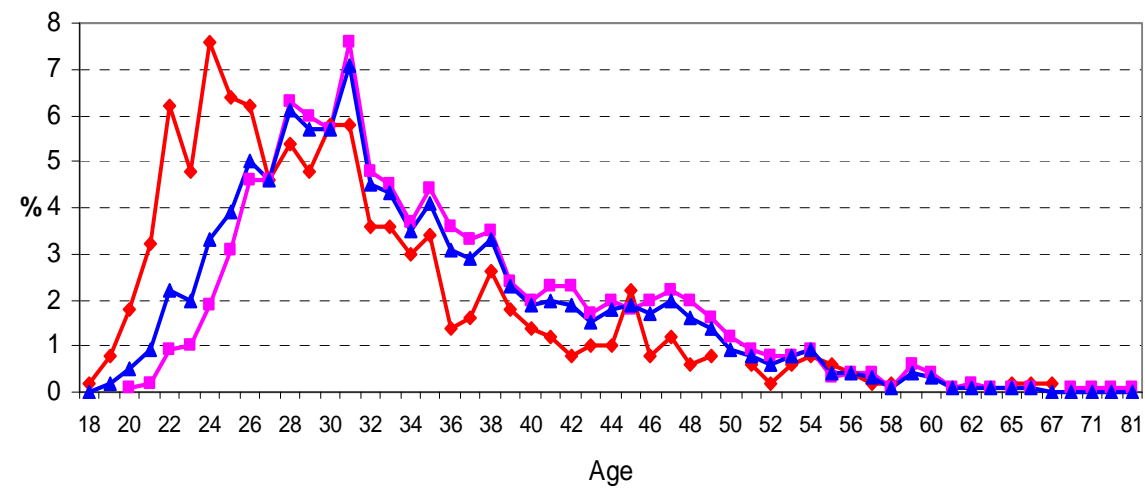

$\longrightarrow$ Rural divorce women $\rightarrow$ Urban divorce w omen $\longrightarrow$ All divorce w omen

Figure 2. Age at divorce of women. ${ }^{4}$

\footnotetext{
${ }^{3}$ Source: Tran Thi Minh Thi. 2011. Study on Divorce Record Profiles at the District People Courts in Hanoi and Hanam provinces in 2000-2009. $\mathrm{N}=.2033$. Pearson Chi-Square $=0.000$ Spearman Correlation $=.000$

${ }^{4}$ Source: Tran Thi Minh Thi. 2011. Study on Divorce Record Profiles at the District People Courts in Hanoi and Hanam provinces in 2000-2009. $\mathrm{N}=.2033$. Pearson Chi-Square $=0.000$ Spearman Correlation $=.000$.
} 


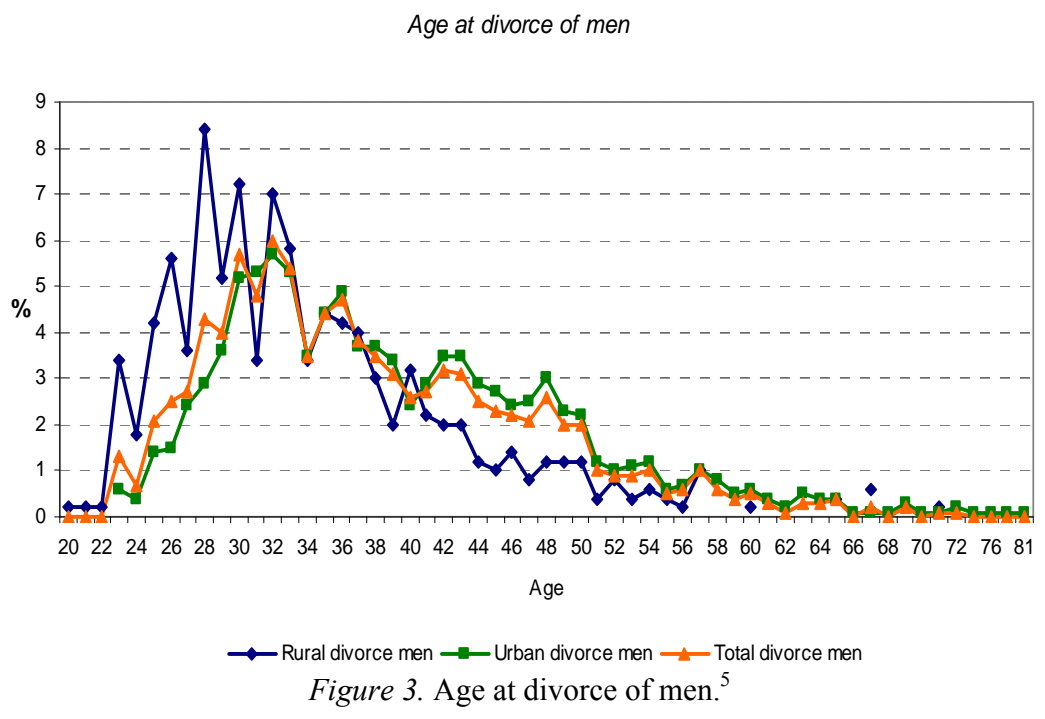

Another dimension of younger age at divorce is small number of children per divorced couple. Number of children of the divorced couple is examined to identify if there is any abnormal of number of children among the divorced. For instance, no children, or too many children may be a cause of marital dissolution. On average, among divorced population, in 10 years, the average number of child per couple is about 1.2 child (see Table 3 ), which is significantly lower than the national TFR (GSO, 2011). It is interesting that, the number of children per divorced couple in the urban areas is higher than the rural areas, which is contradict to the national TFR that TFR of the urban couples are lower than the rural couples. The possible reason is that the rural divorced people tend to divorce earlier than the urban ones.

Table 3

Mean of Number of Children per Divorced Couples by Years ${ }^{6}$

\begin{tabular}{lllllll}
\hline Year & Rural & $\mathrm{N}$ & Urban & $\mathrm{N}$ & Total & $\mathrm{N}$ \\
\hline 2000 & 1.1 & 40 & 1.2 & 88 & 1.2 & 128 \\
2001 & 1.2 & 35 & 1.4 & 92 & 1.3 & 127 \\
2002 & 1.0 & 42 & 1.2 & 87 & 1.1 & 129 \\
2003 & 1.4 & 35 & 1.3 & 98 & 1.3 & 133 \\
2004 & 1.2 & 37 & 1.2 & 119 & 1.2 & 156 \\
2005 & 1.0 & 38 & 1.2 & 149 & 1.1 & 187 \\
2006 & 0.9 & 44 & 1.2 & 164 & 1.1 & 208 \\
2007 & 1.0 & 42 & 1.2 & 147 & 1.2 & 189 \\
2008 & 1.2 & 51 & 1.1 & 42 & 1.2 & 93 \\
2009 & 0.8 & 43 & 1.3 & 25 & 1.0 & 68 \\
Total & 1.1 & 407 & 1.2 & 1011 & 1.2 & 1418 \\
\hline
\end{tabular}

The data in Figure 4 show that, almost couples have 1-2 children. The interesting points are number of couples with no child or more than three children are higher in the rural areas than the urban areas. The proportion

\footnotetext{
5 Source: Tran Thi Minh Thi. 2011. Study on Divorce Record Profiles at the District People Courts in Hanoi and Hanam provinces in 2000-2009. $\mathrm{N}=.2033$. Pearson Chi-Square $=0.000$ Spearman Correlation $=.000$.

${ }^{6}$ Source: Tran Thi Minh Thi. 2011. Study on Divorce Record Profiles at the District People Courts in Hanoi and Hanam provinces in 2000-2009. $\mathrm{N}=.2033$. Pearson Chi-Square $=0.000$ Spearman Correlation $=.000$.
} 
of about $80 \%$ of the urban couples have $1-2$ children while the proportion of the rural couples is about $60 \%$. In the rural area, about one third of the divorced has no child.

Especially, the divorced without child increase strongly recently among rural divorced (see Figure 5), which reconfirm several sociological competing processes in the rural settings. First, more rural divorce at the younger age when they do not have children yet (as also can be seen in the number of couple with more than three children decreased). Second, there are more open-minded and released in social opinions in the rural of marriage and happiness, where women often traditionally sacrifice and suffer. Third, children values are strong and couple tend to dissolute their marriage soon if not being able to have a child.

\section{Number of children of divorce couple by year***}

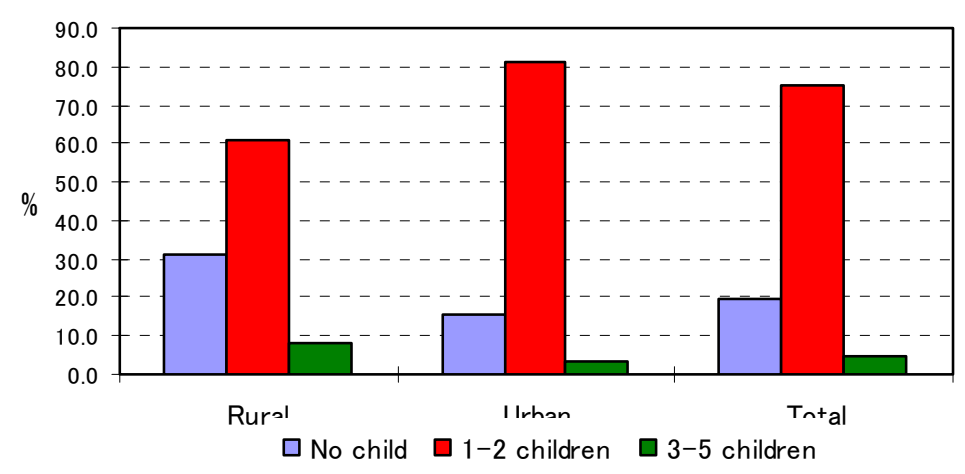

Figure 4. Percentage distribution of number of children by rural/urban differential. ${ }^{7}$
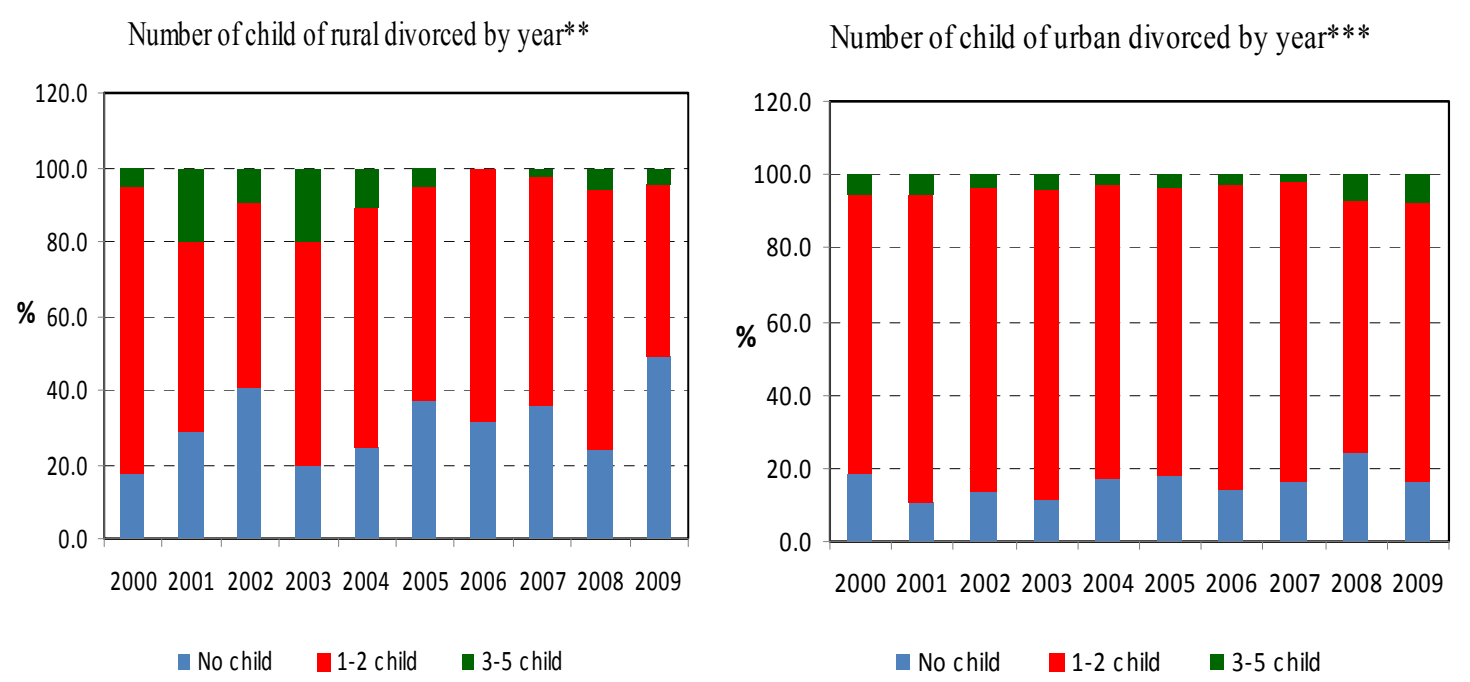

Figure 5. Percentage distribution of number of children by year among rural and urban divorced. ${ }^{8}$

\footnotetext{
${ }^{7}$ Source: Tran Thi Minh Thi. 2011. Study on Divorce Record Profiles at the District People Courts in Hanoi and Hanam provinces in 2000-2009. $\mathrm{N}=.2033$. Pearson Chi-Square $=0.000$ Spearman Correlation $=.000$

${ }^{8}$ Source: Tran Thi Minh Thi. 2011. Study on Divorce Record Profiles at the District People Courts in Hanoi and Hanam provinces in 2000-2009. $\mathrm{N}=.2033$. Pearson Chi-Square $=0.000$ Spearman Correlation $=.000$
} 
In the urban area, number of couples divorce without children remains no much change in last 10 years but the couples with more than three children divorce slightly increase in the recent two years. The age at divorce of the urban couples are older than the rural ones so many of them have children at the time of marriage. They are more easily to access to the health services for child bearing if there is a difficulty (see Figure 5).

It is also interesting that there is a strong increase among divorced people to have no children at the time of divorce; there is a great increase of this among rural divorcees. They are apparently divorcing sooner, when they do not have children yet, since most Vietnamese women have children soon after marriage (Tran, 2007). People are more open to the opinion that marriages should be happy in the rural areas, where women traditionally would sacrifice and suffer. Thus, couples with no children more readily break up due to an unhappy marriage or due to less intimacy in family relations. Also, as the children values and also son preference are strong in the rural Red River Delta under the influence of Confucianism, couples tend to dissolve their marriage soon if they are unable to have a child.

There is a strong increase among divorced people who have no child and less and less people divorce if they have sons only. Thus, having a son may contribute to marital stability when husband is happy with the male offspring and women are released when addressing the marital expectations. Similarly, if couple are not able to give birth, marriage is broken due to that both parties expect the child (see Figure 6).

In the urban areas, the trend of no child was relatively low in 2000-2004 and suddenly peaked in 2005 and remained high in the following years 2006-2007. In the most recent year 2009, couples divorced without child decreased. Even the proportions of couples with sons only were fluctuated by years but tended to increase recently. Thus, child values or son preference might not obviously influence the marital breakup of the urban divorced (see Figure 7).

Viet Nam has a strong boy-preference and this fact leads to a number of issues such as abortions and an imbalance of sex ratio at birth. Therefore, the successful conception and bearing of sons are central to adults' identity and recognition in village everyday life. Villagers who have a succession of daughters bear the stamp of failure. The birth of a son is the most significant moment in a woman's life: It legitimizes her fragile position in her in-laws' family (J. Haughton \& D. Haughton, 1995).

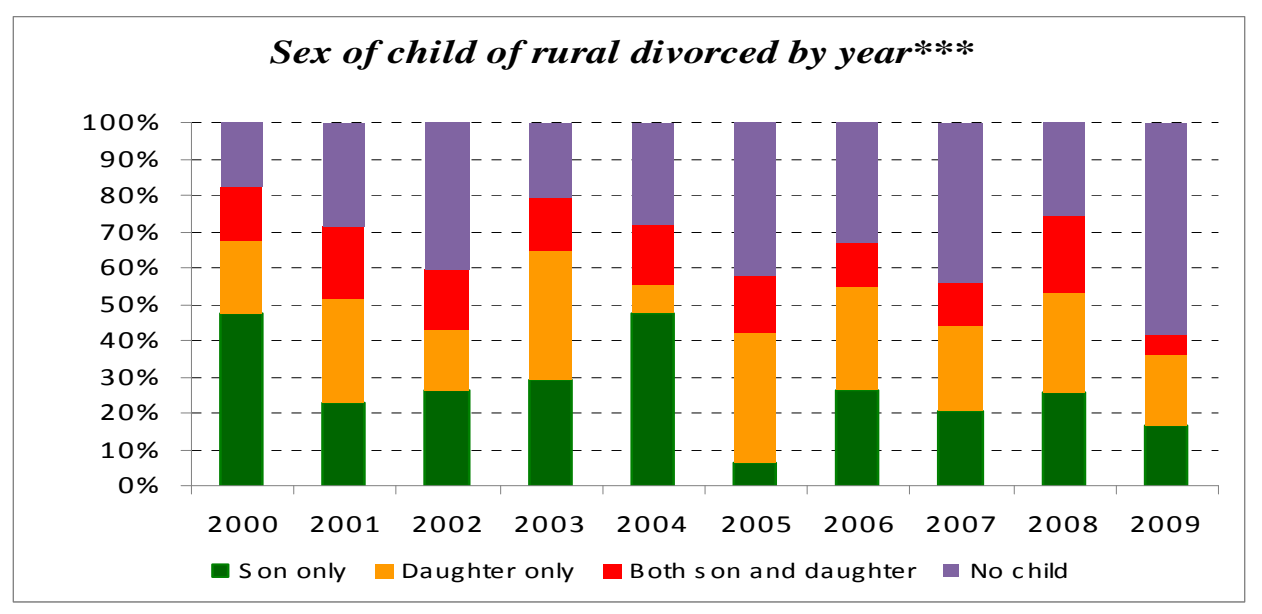

Figure 6. Percentage distribution of sex of children by year of divorce in rural. 


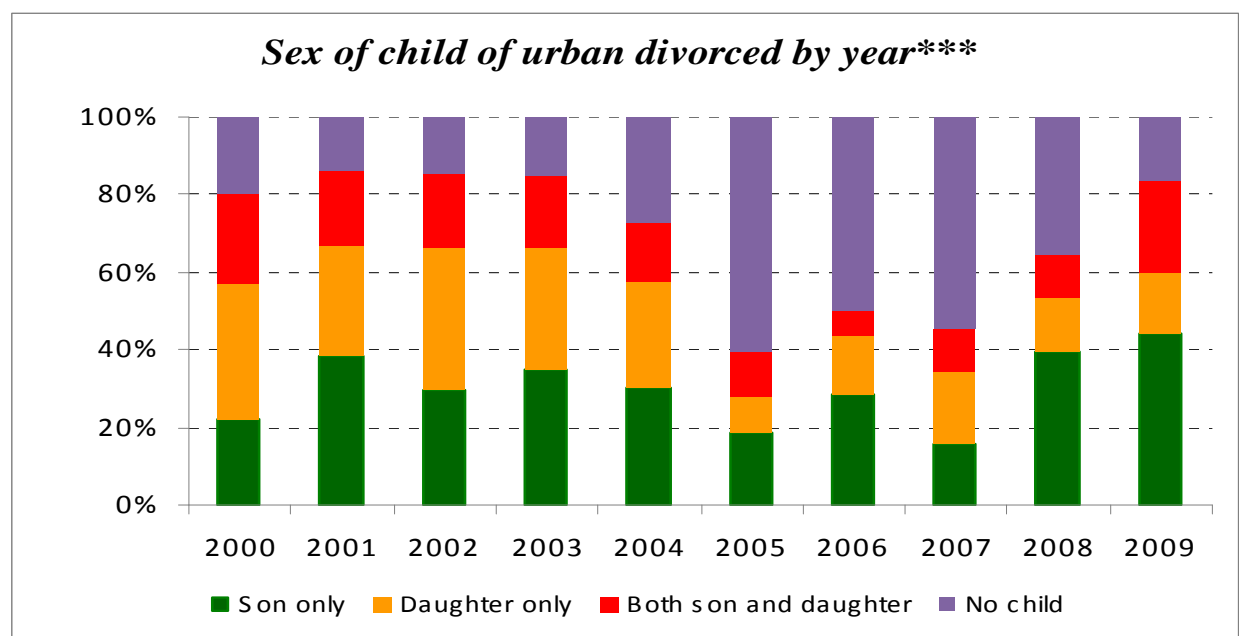

Figure 7. Percentage distribution of sex of children by year of divorce in urban. ${ }^{9}$

As other parts of South Asia, son preference might have been expected to have an attenuated effect on fertility behavior. Hollander (1996) estimates that while son preference in Vietnam is strongly by world standards, its effect on fertility is minor. For example, contraceptive prevalence in Vietnam would increase from $70 \%$ to $77 \%$ and the total fertility rate would decline by $10 \%$ from its level. Vietnamese women generally believe that it is important to have one son to maintain the family ancestral line, but no special desire to have many sons, and the effect of son preference on total fertility is modest. The total fertility rate for Vietnam declined from 5.9 children per woman of reproductive age in period 1975-1980 to 2.09 children in 2014 (GSO, 2014).

The clash between a low demand for children due to family planning policy and a high demand for sons due to culture and social norms has been argued not only to increase son preference but also to increase discrimination against daughters. Daughters receive less investment in terms of finance, time, equipments to education and training than sons in the family. They also are not allowed to join official clan meetings and are not decision makers in the father's family as well as in their husband's clan. They have no chances to access as much as sons to entertainment (Belanger, 2002). There have no significant evidence if having an increase in sex ratio, sex-selective abortion, sex-selective infanticide, and higher mortality of girls than boys during infancy and early childhood since studies on son preference based on secondary data and qualitative surveys. However, data and findings from other education, family, gender, health care service, and job market surveys reflect an undeniable inequality between men and women in society (Belanger, 2002).

Traditionally, Vietnamese women have been at the center of small trade and had the right to hold property and inherit before and after marriage and reinforce each other in many ways. In spite of women's access to economic resources and the socialist attempt to reform gender relations, different perceptions of children's value according to their sex powerfully undermine daughters and elevate sons in Vietnam in the current era of low fertility (Belanger, 2002). Though son preference has modest effect on fertility, it is the fact that it places women (and even men) in a conflict between state law of having maximum two children and cultural and social

\footnotetext{
${ }^{9}$ Source: Tran Thi Minh Thi. 2011. Study on Divorce Record Profiles at the District People Courts in Hanoi and Hanam provinces in 2000-2009. $\mathrm{N}=$. 2033. Pearson Chi-Square $=0.000$ Spearman Correlation $=.000$.
} 
norms of having at least one son. This conflict hypothetically has alternative effects on males and females' reproductive health and sustainability of family institution in Vietnam society.

\section{Finding 3: Social and Economic Hardship During Wars and Before Reform of Divorce Procedures Has Been a Factor}

The data in Figure 8 indicate that, among the divorced people, $40.4 \%$ is poor, $44.4 \%$ is on the average, and $15.3 \%$ is better off. The wealthy of the couple is ranked based on the property they own, which include land, house, savings, and housing facilities (i.e., motorbikes, bike, television, radio, bed, etc), as recorded in the divorce court profiles. In the rural areas, only $12.5 \%$ of divorced is better off while the proportion of the urban divorced is $18.1 \%$. In general, divorced people are usually poor or with average living standard. Divorced people who are rich/better off are higher in the urban areas than in the rural areas.

The wealth ranking distribution of the divorced is fluctuated by years. In the beginning of 2000 s, more better off people divorced than recently. Since the wealth ranking is based on house and property owned by the divorced, it is not necessary to mean people earn less. Inflation and expensive housing make people more difficult of housing and residual assets. In addition, more people get divorce at young ages when the couples donnot have common belongings. In general, the poor and average people get divorce slightly increase by years (see Figure 9).

This section examines the model of living before divorce of the couples with two key options, which are living with the parents and living own their own. The data in Figure 10 show that, the proportion of $57.2 \%$ of the couples living with the parents, and $42.8 \%$ living separately before divorce. The trend of living with parents is more common in the rural area and living separately is higher in the urban area. The proportion of $70.1 \%$ of the rural divorced living with parents before divorces, while the proportion of urban divorced is only $43.4 \%$.

\section{Wealth ranking by residence***}

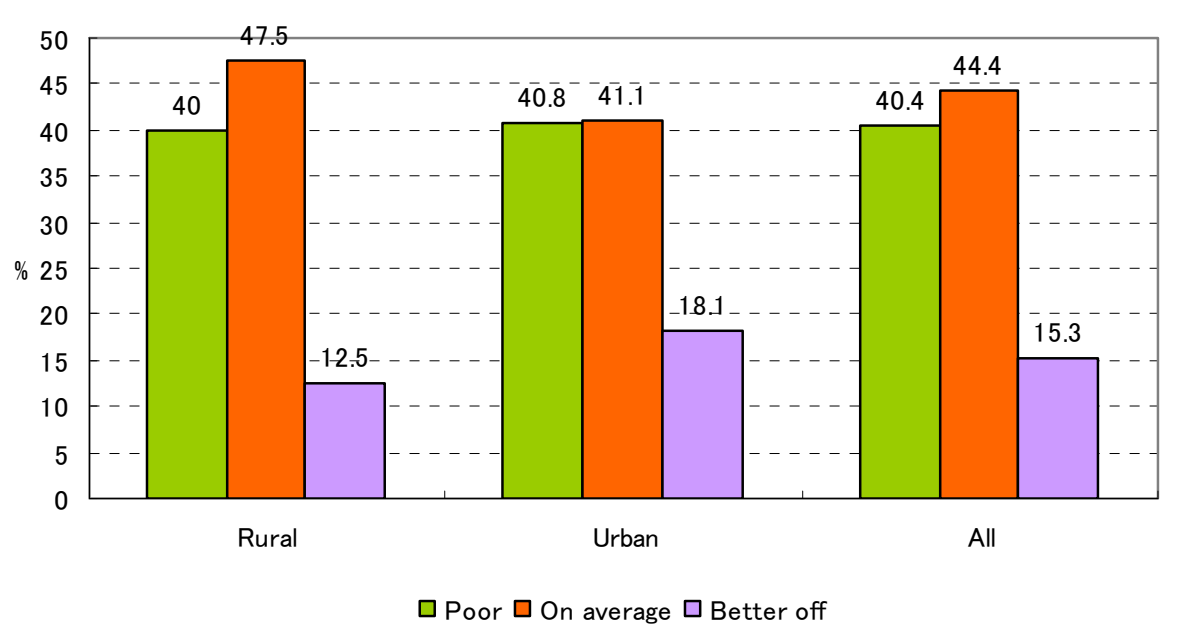

Figure 8. Percentage distribution wealth ranking by rural/urban differential, $\mathrm{N}=708 .{ }^{10}$

\footnotetext{
${ }^{10}$ Source: Tran Thi Minh Thi. 2011. Study on Divorce Record Profiles at the District People Courts in Hanoi and Hanam provinces in 2000-2009. $\mathrm{N}=$. 2033. Pearson Chi-Square $=0.000$ Spearman Correlation $=.000$.
} 


\section{Wealth ranking by years**}

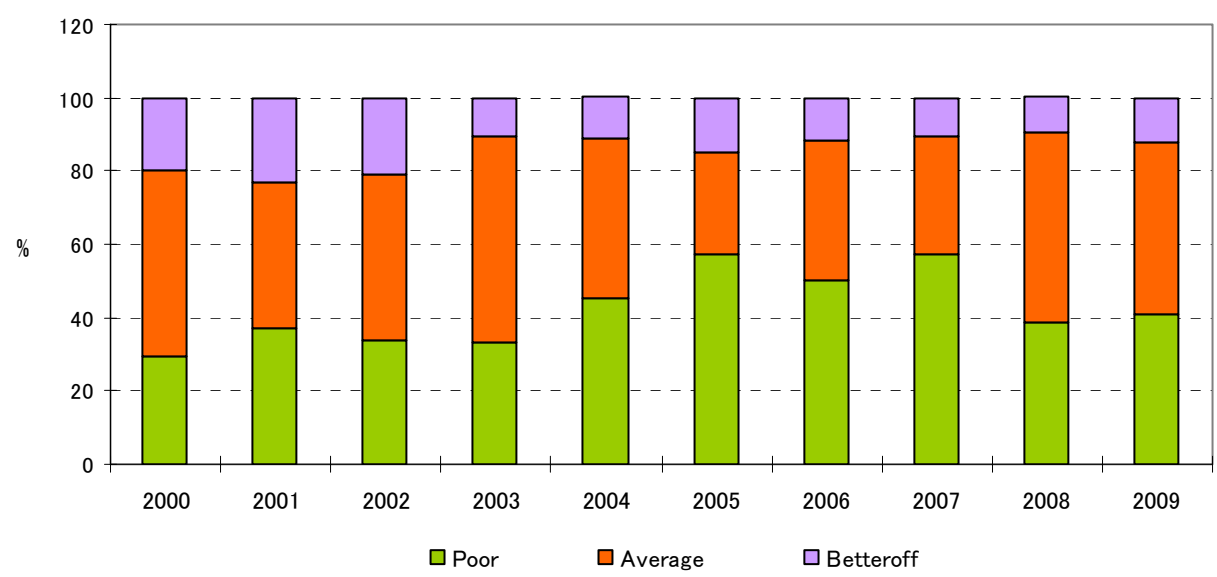

Figure 9. Percentage distribution wealth ranking by years, $\mathrm{N}=708 .{ }^{11}$

Living arrangement by residence***

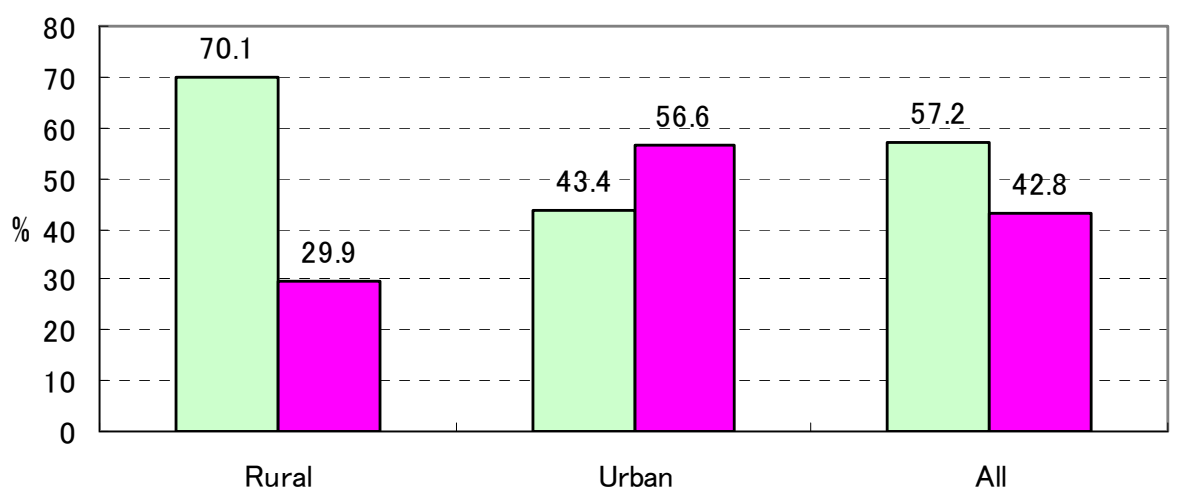

$\square$ Living with parents $\square$ Living on their own

Figure 10. Percentage distribution of living arrangement * rural/urban differential, $\mathrm{N}=708 .{ }^{12}$

Looking at the trend of living arrangement (see Figure 11), it can be seen that the model on living separately is decreasing while the model of cohabitation with the parents is increasing from 2000-2009. For couples divorce from 2000-2004, they report the higher percentages of living alone other than living with their parents. Since 2005 , most divorced couples live with parents. Thus, the characteristic of living arrangement of the divorced is similar to the overall trend in Vietnam, which living with parent is increasing across marriage cohorts (Nguyen, 2011; IFGS, 2008). This may be relevant to the fact that housing is more and more expensive in Vietnam, especially in urban areas like Hanoi city.

\footnotetext{
11 Source: Tran Thi Minh Thi. 2011. Study on Divorce Record Profiles at the District People Courts in Hanoi and Hanam provinces in 2000-2009. $\mathrm{N}=.2033$. Pearson Chi-Square $=0.000$ Spearman Correlation $=.000$.

12 Source: Tran Thi Minh Thi. 2011. Study on Divorce Record Profiles at the District People Courts in Hanoi and Hanam provinces in 2000-2009. $\mathrm{N}=.2033$. Pearson Chi-Square $=0.000$ Spearman Correlation $=.000$.
} 


\section{Living arrangement by years***}

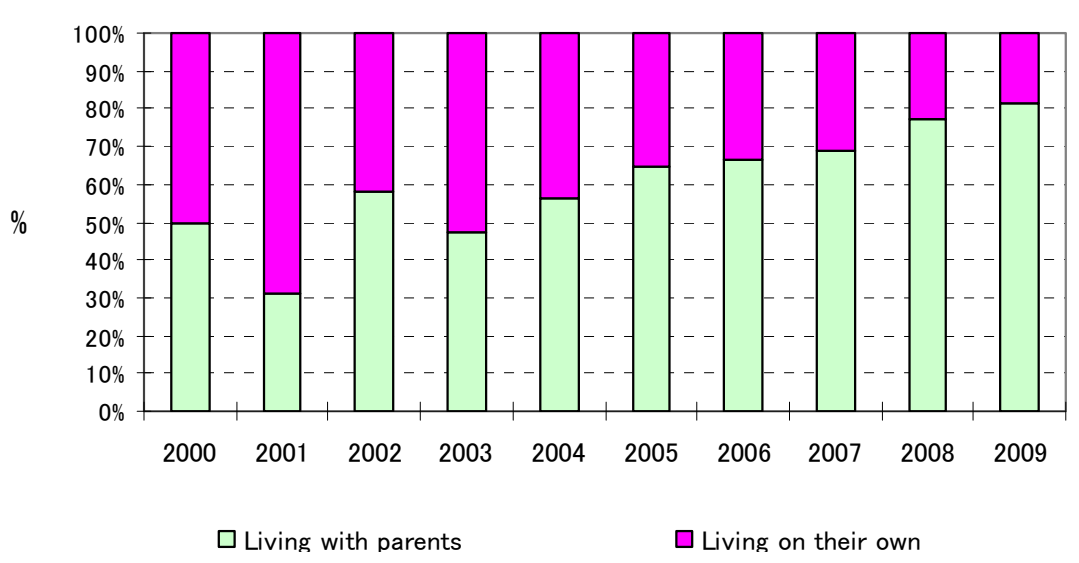

Figure 11. Percentage distribution of living arrangement by year, $\mathrm{N}=708 .^{13}$

In particular, in the rural areas, the trend of living with the parents before divorce is strongly increasing, especially recently. The reasons of most rural couples living with their parents are no house for rent in the rural areas. Since most of rural couple divorce early, and as the general customs, they still live with the parents as living with groom's family right after marriage is almost universal in Vietnam (see Figure 12). In addition, many divorced people in the rural areas are poor, so they cannot afford housing.

Living arrangement of rural divorced by year***

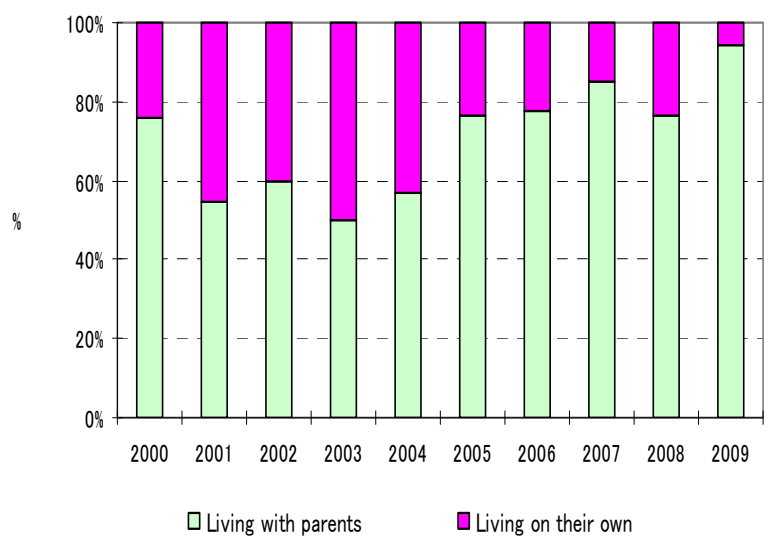

Living arrangement of urban divorced by year***

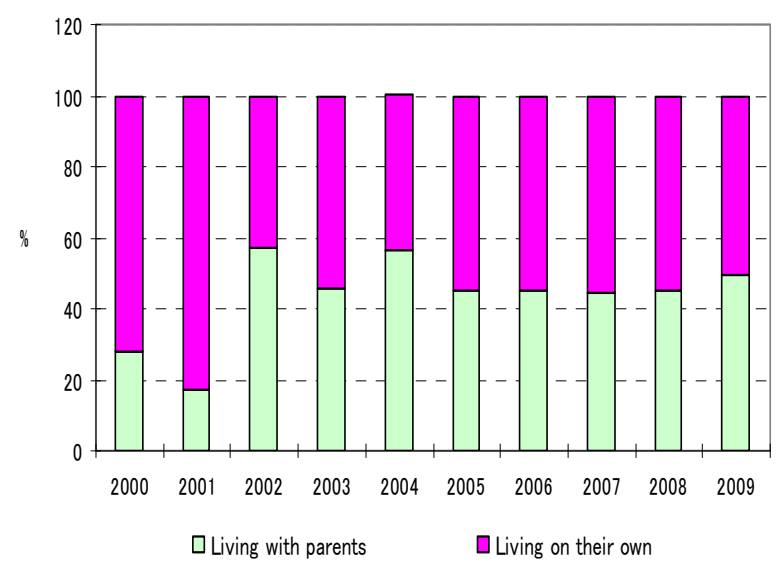

Figure 12. Percentage distribution of living arrangement of rural and urban couples by year of divorce. ${ }^{14}$

Whereas, in the urban areas, more than a half of the couples live separately from the parent before divorce. Thus, the trend of model of living arrangement among urban divorced is different from the ordinary urban couples, that more and more urban couples living with parents after marriage due to housing difficulties (see Figure 12). There may be two reasons. First, the house for rent is more available in the urban settings where the

\footnotetext{
${ }^{13}$ Source: Tran Thi Minh Thi. 2011. Study on Divorce Record Profiles at the District People Courts in Hanoi and Hanam provinces in 2000-2009. $\mathrm{N}=$. 2033. Pearson Chi-Square $=0.000$ Spearman Correlation $=.000$.

14 Source: Tran Thi Minh Thi. 2011. Study on Divorce Record Profiles at the District People Courts in Hanoi and Hanam provinces in 2000-2009. $\mathrm{N}=.2033$. Pearson Chi-Square $=0.000$ Spearman Correlation $=.000$
} 
couple prefer to live alone under the influences of Western cultural values of individual freedom. Second, the proportion of the rich with house ownership divorced is higher in the urban areas. And also, since age at divorce of urban couples are older than rural ones, and by that age, they may achieve a certain social status with certain economically independence, which allow them living separately from parents.

Divorced people are usually poor or with average living standard. The percentage of divorced people who are rich is higher in urban areas. Also, since divorce tends to be soon, within five years of marriage, most of divorcees had no property or house. The majority of divorced people lived with parents before divorcing. The trend of living with parents is more common in the rural area and living independently is the trend in urban areas. In particular, in the rural areas, the trend of living with parents before divorce is strongly increasing by year. Most rural couples that divorce do so early. Living with parents, particularly with the groom's family right after marriage, is almost universal in Vietnam. In addition, many divorced people in rural areas are poor, so they cannot afford a house. Houses for rent are not available in rural settings.

\section{Conclusion and Discussion}

For a long time, Confucian ideology and feudal marriages, which included arranged marriages, limited premarital intimacy; the status of women was low, but as women's economic role became significant the risk of divorce increased. However, low educational attainment and women's limited rights in divorce and lack of dependence were characteristic of the status of women under the Confucian regulations; and women's readiness to sacrifice for men to fight in the battlefield during the Vietnamese historical chaos, and women's responsibilities for childcare and domestic chores at home kept divorce rates low. In the other words, traditional Vietnamese culture frowned on divorce.

There was a direct transfer from feudalism to socialism in 1945, followed by great changes in legal settings, which formulated new perceptions of modern marriage and family life. These were based on the principles of love marriage, monogamy, and gender equality. In the other words, the Vietnamese State played an important role in the formulation of the marriage patterns by introducing policies and laws on marriage and the family, and other socio-economic development policies. The policy changes paralleled economic development and modernization, but in fact, the unique power of the communist party and the government in managing society made the state the foundation for all social changes, including changes in marriage and family relations. The old values and perceptions of family are mostly banned and new/modern values and perceptions have been formed due to legal changes.

However, following decades of wars (i.e., 1945-1975) and economic hardship, social crises caused by a command, subsidized, bureaucratic central-planned economy, and international isolation (1975-1986) were believed to impede modernization and social awareness of modern marriages. Political independence was understood on a personal level as offering a release from the bonds of irrational customs and hierarchies, and the achievement of national sovereignty and self-determination was associated with the development of individual subjectivity adapted to the circumstances of the modern social order. Modern Vietnam can be seen as a "shortcut" modernity, in which capitalist industrialization was skipped, but it also reflects one main feature of modernization and industrialization, which is a "shortened" strategy. Modernization, on the one hand, ended arranged marriages and led to greater freedom in mate selection, increasing ages at marriage, and educational 
expansion. Theoretically, these changes contributed to marital stability and a decline in divorce. On the other hand, the most important contribution of modernization in marriage and family in Vietnam is the role of state in promoting gender equality, a higher status of women and greater participation by women in the labor force. These reforms greatly improved women's voice and status. Subsequently, more women walked out of trouble marriages; this led to an increase in the number of divorces.

The Renovation (Doimoi) introduced new ways of thinking, transforming society from a command, subsidized, bureaucratic central-planned economy and a closed-door policy toward a market-oriented economy and an open-door policy, in a stage of shortened, catch-up modernization. Although modernization theory has argued that economic development brings pervasive cultural changes (including higher divorce rates), values regarding the family are also influenced by the persistence of traditional values and the introduction of a political ideology, designed to change traditional approaches to marriage and divorce.

Individualism and collectivism are cultural dimensions related to the prevalence of divorce and patterns of divorce. Collectivism is a social pattern that places the highest value on the interests of the group. Collectivists view themselves as interdependent and closely linked to one or more groups. Norms, obligations, and duties to groups are collectivists' primary concerns, and they tend to place a high value on group harmony and solidarity. Respectfulness and cooperation are common collectivist traits. When personal goals conflict with group norms, collectivists tend to favor conforming to group norms (Triandis, 1995).

Collectivist cultures have lower tolerance towards divorce. Also, marriage positively affects the life satisfaction of people in collectivist cultures more than those of individualist cultures. This is a possible reason why there is a lower divorce rate in collectivist cultures than in individualist cultures (Triandis, 1995). At times when conservative values and self-containment were prevalent, society placed great value on collectivism and peer pressure had enormous influence. Social scrutiny forced many couples to stay in unhappy marriages. National policies, which reflected the moral values of that time, also dissuaded people. To get a divorce, the couple had to go through a very complicated procedure since there was a strong pressure against divorce. The goal of women in collectivist culture is more likely to be marriage and children, while the goal of women in individualist countries is more likely to be success in their careers. Therefore, the women in collectivist society are more likely to be satisfied with their marriage than women in individualist cultures.

The socio-economic miracle that followed the country's opening to the outside world and Renovation after 1986 have dramatically changed social mores. Getting divorced no longer carries the social stigma it once did. Vietnam's transformation to a market economy and modernization also began to reshape lifestyles and values, including those related to marriage and divorce. The process of modernization untied individuals from traditional viewpoints and perceptions of marriage and family. Society is believed to be in transition to modern lifestyles.

Collectivism has become weaker and individualism has become stronger. With material comforts vastly improved, people are no longer satisfied with marriages that merely fulfill the need to carry on the family line and requiring obedience and sacrifices from women.

People in individualistic societies value self-interest more than the in-group interests, while people in collectivistic cultures value group-interest more than self-interest. The more individualistic a culture, the higher 
the divorce rates (Triandis, 1995). After Doimoi, material affluence has led to more individualistic views that in turn have led to higher divorce rates. Moreover, Vietnamese cultural beliefs have been transformed from a group-orientation to a more individualistic orientation. Modernization has brought greater autonomy to the Vietnamese. Divorce is becoming a reflection of autonomy and rational decisions to pursue individual happiness. Urbanization through economic development promoted not only family transition but also changed ways of finding a partner. Despite the norm of arranged marriages, after legal changes and especially after Renovation, younger people often tended to voluntarily select their own partners. This transition from arranged marriage to love match in marriage style contributes to an increase in divorce by untying the connection of married couples and the other people concerned.

In general, divorces in Vietnam report both traditional and modern styles, and some of them are competing between the transitional processes. Due to socio-structural and legal changes under the increasing modernization process, individuals perceive more liberal values in marriage, family, and divorce. Familialism remains significant but individualism is increasing. The disparate coexistence of various levels of tradition, transitional and modern values in the context that new institutions have not perfected while old institutions remain existent is the general model of divorce in contemporary Vietnam.

\section{References}

Annual Statistic Records, 2000-2010. National People Supreme Court, Vietnam.

Annual Statistic Records, 2000-2009. The People Court, Binh Luc district, Ha nam province, Vietnam.

Annual Statistic Records, 2000-2009. The People Court, Cau Giay district, Hanoi capital, Vietnam.

Barbieri, M., \& Belanger, D. (2009). Reconfiguring families in contemporary Vietnam. Contemporary issues in Asia and the Pacific. Stanford, California: Stanford University Press.

Beck, U. (1992). Risk society: Towards a new modernity. London: Sage Publication.

Becker, G. S., Elisabeth, M. L., \& Robert, T. M. (1977). An economic analysis of marital instability. The Journal of Political Economy, 85(6), 1141-1187.

Belanger, D. (2002). Son preference in a rural village in North Vietnam. Studies in Family Planning, 33, 321-334.

Chang, K. S. (2010). Individualization without individualism: Compressed modernity and obfuscated family crisis in East Asia. Journal of Intimate and Public Spheres. (Asian and Global Forum. Kyoto University Global COE Program. Pilot Issue. March 2010).

Do, L., \& Phan, T. M. H. (2002). Collectivism, individualism and "the self" of the Vietnamese today. Hanoi: Chinh Tri Quoc Gia Publisher.

Goode, W. J. (1971). World revolution and family patterns (2nd ed.). New York: Free Press

Goode, W. J. (1993). World changes in divorce patterns. New Haven: Yale University Press.

Goode, W. J. (1963). World revolution and family patterns. New York: Free Press.

GSO (General Statistic Office). (2014). Statistical hand book of Vietnam.

Haughton, J., \& Haughton, D. (1995). Son preference in Vietnam. Studies in Family Planning, 26, 325-337.

Hirschman, C., \& Teerawichitchainan, B. (2003). Cultural and socioeconomic influences on divorce during modernization: Southeast Asia: 1940s to 1960s. Population and Development Review, 29(2), 215-253

Hollander, D. (1996). Son preference remains strong among Vietnamese women, but has only a modest effect on fertility. International Family Planning Perspective, 22, 84-85

IFGS (Institute for Family and Gender Study). (2008). Survey on Vietnam families 2006: General report.

Jones, G. W. (2003). The "flight from marriage" in South-East and East Asia pp.14. Singapore: Asian MetaCentre for Population and Sustainable Development Analysis.

Le Ngoc Van. (2006). Ve quan he hon nhan hien nay (Today's marriage relations). Tap chi Nghien cuu Gia dinh va gioi, 16(2), 3-15. Lee, G. (1982). Family structure and interaction: A comparative analysis (2nd ed.). Minneapolis: University of Minnesota Press. 
Nguyen, H. M. (2008). Age patterns of first marriage. In T. D. Luân, H. Rydstroom, and W. Burhoorn (Eds.), Rural families in transitional Vietnam. Hanoi: Social Sciences Publishing House.

Nguyen, H. M. (2011). Post-marital living arrangements in rural Vietnam. In T. D. Luân, H. Rydstroom, and W. Burhoorn (Eds.), Rural families in Doimoi Vietnam. Hanoi: Social Sciences Publishing House.

Ochiai, E. (2011). Unsustainable societies: The failure of Familialism in East Asia's compressed modernity. Historical Social Research. Special, (136). HSR, 36(2011 2), 219-246.

Trần, T. M. T. (2011). Divorce in the rural Red River Delta:A case study of individual choices and the forces of tradition (Chapter 7). In T. D. Luân, H. Rydstroom, and W. Burhoorn (Eds.), Rural families in DOIMOI Vietnam (English and Vietnamese). Hanoi: Social Sciences Publishing House.

Trần, T. M. T. (2007). Các yếu tố tác động đến tuổi sinh con đầu tiên (Determinants of age at first birth in Vietnam). Tạp chi Nghiên cúu Gia đình và Giới, Số 4.2007.

Trần, T. M. T. (2014). Divorce in contemporary Viet Nam: A socio-economic and structural analysis of divorce in the Red River Delta in 2000s. Hanoi: Social Sciences Publishing House.

Trần, T. M. T. (2010). Divorce in Rural Red River Delta. Journal of Family and Gender Studies, 1.

Triandis, H. C. (1995). Individualism \& collectivism. New directions in social psychology. Boulder, CO, US: Westview Press. 